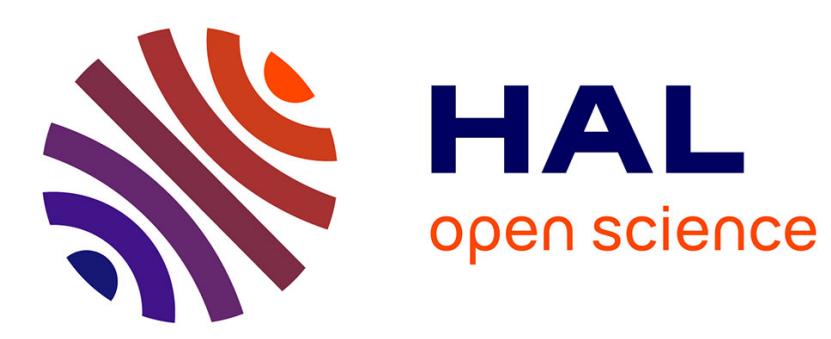

\title{
Managing knowledge management tools: a systematic classification and comparison
}

Yang Xu, Alain Bernard, Nicolas Perry, Lian Lian

\section{To cite this version:}

Yang Xu, Alain Bernard, Nicolas Perry, Lian Lian. Managing knowledge management tools: a systematic classification and comparison. The 2011 International Conference on Management and Service Science (MASS), Aug 2011, China. pp.1-4. hal-00804267

\section{HAL Id: hal-00804267 https://hal.science/hal-00804267}

Submitted on 25 Apr 2013

HAL is a multi-disciplinary open access archive for the deposit and dissemination of scientific research documents, whether they are published or not. The documents may come from teaching and research institutions in France or abroad, or from public or private research centers.
L'archive ouverte pluridisciplinaire HAL, est destinée au dépôt et à la diffusion de documents scientifiques de niveau recherche, publiés ou non, émanant des établissements d'enseignement et de recherche français ou étrangers, des laboratoires publics ou privés. 


\section{Managing knowledge management tools: a systematic classification and comparison}

\author{
Yang XU \\ Department of Information Management \\ Peking University \\ Beijing, China \\ yang.xu@pku.edu.cn \\ Nicolas PERRY \\ Mechanical and Engineering Institute of Bordeaux \\ University of Bordeaux 1 \\ Bordeaux, France \\ nicolas.perry@u-bordeaux1.fr
}

\author{
Alain BERNARD \\ IRCCyN \\ Ecole Centrale de Nantes \\ Nantes, France \\ alain.bernard@irccyn.ec-nantes.fr
}

\author{
Lian LIAN \\ Department of Transportation and Logistics \\ Dalian University of Technology \\ Dalian, China \\ lilian591@gmail.com
}

\begin{abstract}
Knowledge management (KM) is playing an important role in commercial and academic activities, and people are usually armed with effective KM tools for implementation. On one hand, KM tools can facilitate KM activities; however, on the other hand, with the "explosion" of KM tools development, people may feel confused about which to choose or which is more suitable. As a result, KM tools should be managed, so this paper aims at making a systematic classification and comparison research and proposes a KM tools selection strategy based on a point of view on knowledge lifecycle.
\end{abstract}

Keywords-knowledge management, e-tools, classification, comparison

\section{INTRODUCTION}

Knowledge management $(\mathrm{KM})$ is becoming more and more crucial in current commercial and academic activities [1]. As a result, various KM tools have been developed one after another to help people deal with KM problems. Effective usage of KM tools may make knowledge management more efficient, such as make knowledge more easily accessible, shared, maintained, used, reused, etc.

Different KM tools integrate different techniques to capitalize, share and manage knowledge, and link people to support collaborative work. By using appropriate KM tools, people can learn more from other's experience and knowledge to find and create better solutions within less time, money and effort, and they can more freely work in collaboration to achieve a common task or innovation with fewer barriers.

As knowledge management contains a large amount of domains, subjects and activities, KM tools come out one after another and recently reach a number that is so large that they should be managed. Different KM tools have different stresses, so choosing the right KM tool is important to make KM activities more efficient, otherwise, cost and burden brought by the tools will significantly reduce their value in application. For this purpose, this paper aims at managing the KM Tools by making a systematic classification and comparison.

\section{REALIZING KM BY KM TOOL}

With the increasing impact of knowledge on commercial and production behaviors, innovation and collaboration have to adapt and readapt to the new ways of knowledge capitalization, knowledge sharing, knowledge use, etc. - a series of knowledge management - to add value [2]. In order to help people seek more breakthroughs in knowledge management, various KM tools have been developed to assist.

Knowledge management adds significant value to today's business world [3]. For example, in a collaboration environment, knowledge sources might be distributed both geographically and logically, thus, KM tools can help knowledge user browse and consolidate different knowledge.

The requirements of $\mathrm{KM}$ activities impulse the emergence of diverse KM tools, and on the other hand, the prosperity of $\mathrm{KM}$ tools opens new perspectives and change behaviors in knowledge management. For example, in a production system based on multi-site cooperation, globalized decisions should be made by taking all useful information and knowledge into account, and such complex systems are usually difficult to optimize. In such cases, people are always seeking KM tools for help, such as KM tools for knowledge retrieval, for knowledge sharing, etc. At the same time when people are enjoying the convenience brought by those KM tools, they might have to change their habits and ways to do things as well. For example, with a tool that can facilitate knowledge sharing, people should be aware of the fact that they have to be more careful when sending out information and/or knowledge. People must be more careful about the security problems (take the internet as example, it can facilitate knowledge sharing more than ever, but at the same time, it brings severe security problems that people have never met before), the accuracy of 
information and/or knowledge (with the faster and wider spread of information and/or knowledge which are sent by someone, he/she should be more responsible as well), etc.

Many existing KM tools are designed to try to solve "every" problem, as a result, they are more or less complicated, and they might bring an opposite effect: make things more complex, although they are expected to make things simple. Especially for small and medium enterprises (SME), what they need is a knowledge management framework as simple (including cheap to configure, easy to operate, etc.) as possible, solving problems without overloading their activities too much [4]. During the lifecycle of a knowledge management project, there are usually several phases, such as knowledge retrieval, knowledge capitalization, knowledge creation, knowledge sharing, etc., based on this point of view, this paper will introduce six major classes of KM tools, giving illustrations of several concrete KM tools as example. Through the systematic classification and comparison, it aims at giving an overview to the development of $\mathrm{KM}$ tools and managing $\mathrm{KM}$ tools to facilitate their further applications.

\section{KM TOOLS CLASSIFICATION AND COMPARISON}

A successful KM tool will obviously provide sustainable competitive advantage to the organization that applies it, but selecting the "right" KM tool is not an easy task. KM is usually implemented in an extremely complex context and highly dynamic environment. Meanwhile, KM covers a very broad field consisted of a number of relevant or irrelevant areas, such as intelligence capital, data mining, relationship management, organizational behavior, enterprise culture, etc. Furthermore, different KM tools' focuses and ranges of functionality vary a lot. As a result, finding a suitable $\mathrm{KM}$ tool to meet the company's requirements is quite difficult, so it is necessary to make a systematic study on KM tool classification and comparison.

According to their essential functions, KM tools are mainly classified into five types, namely knowledge capitalization, knowledge sharing, knowledge retrieval, consultant, and query.

\section{A. KM Tools for Knowledge Capitalization}

Rothwell defined innovation as a "process of know-how accumulation", so knowledge capitalization is a fundamental step for knowledge-creation and it can start a new knowledge life cycle [5]. In knowledge capitalization, the balance between codification and maintenance of complexity should always be taken into account. Here are some well-developed tools.

- ACQUIRE® from Acquired Intelligence Inc. is a knowledge acquisition system that uses a step-by-step method to capture expertise in expert systems for different applications (e.g., desktop, client/server or web) [6]. It captures rule-based knowledge so that it can be easily integrated into different applications. It applied some structured approaches in order to enable people to accomplish their own knowledge-based utilizations.

- XpertRule ${ }^{\circledR}$ developed by XpertRule Software Ltd. is expert system software which can provide advanced management based on business rules and helps users to capture the knowledge of an organization such as rules, processes, experience, skills, etc. and create automated solutions of high quality for complex decision making problems [7]. It captures knowledge of various domains, such as risk assessment, performance improvement, advising, selling and products/services support, complying with regulations, policies, laws and legislation.

\section{B. KM Tools for Knowledge Sharing}

KM tools for knowledge sharing help people work together and share information, for example, virtual on-line meetings and data sharing using bulletin board, chat, audio, video, discussion groups, file sharing tools, instant messaging, etc. These tools bring geographically dispersed teams together for virtual meetings across great distances, which results in: tremendous time and cost savings, great decrease in travel requirements, faster and better decision making, and improved communications flow throughout the organization. As in modern cooperation pattern different agents are dynamic and operate in parallel over great distances, KM tools for knowledge sharing improve parallel processing, knowledge worker productivity, coordination, and adaptiveness. Some of them speed up communication and collaboration among team members by providing centralized storage of knowledge.

- Centric Insight ${ }^{\circledR}$ developed by Centric Software Inc. facilitates people to search and share information as if it were created locally [8]. It allows people to find knowledge in a secure environment and to access critical data as needed. The advanced pattern for guided search makes it easier to find knowledge quickly and efficiently.

- Open Text Corporation provides a KM tool to enhance the systems' capabilities for knowledge sharing based on several advanced techniques, such as web crawling, virtual folders, automatic classification and intellectual searching [9].

\section{KM Tools for Knowledge Retrieval}

In this increasingly global and virtual world full of ebusiness, people are spending much time and energy in "finding the right knowledge", so how to ameliorate knowledge retrieval processes is one of the biggest challenges and is seriously considered in many KM tools.

- Open Text Discovery Server is a powerful search engine of various features for publishing large quantities of dynamic and customized information [9]. It incorporates several effective methods in flexible filtering and intelligent search tools for enterprise information retrieval.

- Wong et al. have developed a system that allows users across a company to retrieve necessary knowledge and undertake relevant activities [10]. The system can be regarded as a knowledge-based repository which can search and analyze relevant records, then provide users with an analyzed and summarized result - the retrieved knowledge. 


\section{KM Tools for Consultant}

Some KM tools aims at providing tailored consults to the needs of customer and market, and they may serve as decision support systems. In most cases, these tools are used under experts' guidance and man-to-man communications are included.

- NeuroDimension Inc. mainly focuses on "learning" capacities in knowledge capitalization by using neural networks, which can perform tasks intelligently, similar to those performed by human brain. The process of acquiring knowledge is accomplished through learning and then storing knowledge within inter-neuron connection strengths known as synaptic weights [11]. Different products developed by the company can be used to apply neural network technology to real-world applications, such as detecting characteristics in image, controlling medical devices based on biofeedback, identifying video characteristics, assembling common characteristics in large amounts of data, determining relationship between business factors to forecast effects of changes (prices, costs), predicting prices based on previous performance, etc.

- The Centric 8 PLM and Sourcing Solutions ${ }^{\circledR}$ from Centric Software Inc. are focused on the needs of consumer product industries that typically have short product lifecycles [8]. It represents the culmination of proven experience in developing innovative product lifecycle management (PLM) solutions. It can provide innovative solutions that are easy to use and fast to deploy.

- Cicero ${ }^{\circledR}$ provides business integration software and an enterprise-wide view on their business information processes [12]. It enables users to meet the companies' need on their information systems and the transformation of human interaction and cooperation across the enterprise. It can facilitate data flows to communicate between different types of applications, eliminating redundant data and mistakes. In addition, it also provides hand-in-hand technical support, employee training and consulting services with feasible solutions to consumers.

- AskMe ${ }^{\circledR}$ knowledge management solutions from Realcom US Inc. focus on helping companies manage their internal knowledge and expertise [13]. Successful KM solutions need to be customized to meet companies' proper business, technical and cultural needs, so solutions are delivered based on the analysis results about companies' needs from both technical and cultural perspectives. With a lifecycle-based view on the projects, AskMe ${ }^{\circledR} \mathrm{KM}$ systems create a knowledge networking environment integrating all project stages, from requirements definition to usage monitoring.

\section{E. KM Tools for Query}

KM tools which focus on query allow us to respond efficiently to each potential interrogation with an extremely short delay. They can provide the answer of the exact knowledge to the users' requirement, wherever it is and whenever they need. KM tools of this type are usually integrated in e-Response systems which are constructed using a number of artificial intelligence (AI) and semantic web technologies [14].

- Open Text Federated Query Server provides a single access point to query multiple repositories to obtain a unified set of results, enabling instant access to information from across the enterprise [9]. It is especially useful to deal with distributed problems.

- AQUA developed by Open University is an automated question answering system which allows users to ask questions and receive an answer in real time [15]. At the same time, a context is also provided to help users validate the answer. It includes query interface, natural language processing parser, the WordNet as dictionary, knowledge bases of different domains, logic interpreter, failure analysis subsystem, search engine, answer extraction and selection.

\section{F. KM Tools for Knowledge Creation}

Creation activities in KM are very crucial, and it determines how knowledge value can be added and increases. As a base of creating usable knowledge, people must firstly understand and master the existing knowledge, and on the other side, knowledge should be generated and managed in a way that is comprehensible and applicable by others. The following KM tools aims at assisting knowledge worker in knowledge creation by exhibiting knowledge in an intuitive and visual way.

- AutoCAD ${ }^{\circledR}$ design and documentation software from Autodesk Inc. is a well-known Computed-Aided Design (CAD) tool, and it can exhibit knowledge intuitively which is helpful in idea exploration knowledge creation [16].

- TurboCAD ${ }^{\circledR}$ developed by IMSI/Design LLC. is a flexible KM tool which can meet the requirements of most CAD users [17]. Its modeling techniques convert implicit ideas to explicit images, which can facilitate the processes of drafting, design and modeling. These processes belong to the main knowledge creating activities in mechanics and architecture projects.

- Microsoft Office Visio ${ }^{\circledR}$ from Microsoft Corporation provides diagramming solutions that help people visualize their everyday work [18]. Its core idea is to transform existing knowledge in the form of complicated texts and tables to flowcharts and diagrams which can display insights in an easier, more attractive and intuitive way, so that managers can better understand complex information, processes and organizational systems, which are helpful in exploring new ideas.

One of the most important goals for classification is to "divide" a complex thing to some simpler things. Choosing the most suitable KM tools among so many existing $\mathrm{KM}$ tools, whose number is increasing sharply, in the sophisticated and dynamic knowledge-based contexts, is such a complex thing. 
By classifying KM tools into six different classes, we can facilitate the work of "selecting the best". Moreover, classification can help people manage different KM tools differently, and propose different development strategies for different classes of KM tools.

For the comparison of these different classes of KM tools, this paper adopts the point of view of knowledge lifecycle (c.f. Figure 1). Obviously, different stages in a lifecycle may cross one another, so the classification of KM tools is not "absolute", in other word, a KM tool which belong to one class may also belong to another. In fact, many KM tools are designed and developed for several purposes, and the classification strategy introduced in this paper helps to identify one of the focuses of a given $\mathrm{KM}$ tools.

As shown in Figure 1, the choice of different classes of $\mathrm{KM}$ tools is related to different stages of the knowledge lifecycle. For example, in the stage of knowledge gathering, KM tools from the classes of "knowledge retrieval" and "knowledge capitalization" should be chosen. From this point of view, when choosing KM tools, it is not their technical contents to be compared, but their application context.

\section{SUMMARY}

This paper mainly deals with the problems of KM tools classification and comparison, and the results of them can help people select the most suitable KM tools. When facing a KM problem, it is always very important and useful to find the "right" tool for help, because the right tool can not only help people deal with KM problems more efficiently, but also change people's behaviors, because KM activities are always human-related and there are always interactions between human and KM tools. For further perspectives, we should taking into account that different enterprises have their own knowledge base and proper KM behaviors with corresponding value indicators. Moreover, it will be very interesting to make a comprehensive research on the relationship between different phases of the knowledge lifecycle and the eight steps of MARISKA (Methodological Algorithm for Requirement to Indicators Supporting Knowledge Activities) [19] [20] so as to choose, apply and develop appropriate KM tools.

\section{REFERENCES}

[1] A. Bernard, and S. Tichkiewitch, "Methods and tools for effective knowledge life-cyclemanagement", Berlin: Springer, 2008.

[2] Y. Xu, and A. Bernard, "Quantifying the value of knowledge within the context of product development", Knowledge-Based Systems, Vol.24, No.1, pp.166-175, 2011.

[3] M. Du Plessis, "Drivers of knowledge management in the corporate environment", International Journal of Information Management, Vol.25, No.3, pp.193-202, 2005.

[4] J. LeDuigou, A. Bernard, N. Perry, and J.C. Delplace, "Application of PLM processes to respond to mechanical SMEs needs", Proceedings of the $20^{\text {th }}$ CIRP Design Conference, Nantes, France, 2010.

[5] R. Rothwell, "Industrial Innovation: Success, Strategy, Trends", in M. Dogson and R. Rothwell (Eds) "The handbook of industrial innovation". Cheltenham: Edward Elgar Publishing, 1994.

[6] http://www.aiinc.ca

[7] http://www.xpertrule.com

[8] http://www.centricsoftware.com

[9] http://www.opentext.com

[10] S. C. Wong, R. M. Crowder, N. R. Shadbolt, and G. B. Wills, "Knowledge Management for a Large Service-Oriented Corporation", Proceedings of the $6^{\text {th }}$ International Conference on Practical Aspects of Knowledge Management, pp. 326-337, Vienna, Austria, 2006.

[11] http://www.nd.com

[12] http://www.ciceroinc.com

[13] http://www.realcom-inc.com

[14] S. Potter, Y. Kalfoglou, H. Alani, M. Bachler, S. Buckingham Shum, R. Carvalho, A. Chakravarthy, S. Chalmers, S. Chapman, B. Hu, A. Preece, N. Shadbolt, A. Tate, and M. Tuffield, "The Application of Advanced Knowledge Technologies for Emergency Response", Proceedings of 4th International Information Systems for Crisis Response and Management, Delft, The Netherlands, 2007.

[15] http://kmi.open.ac.uk/projects/akt/aqua

[16] http://usa.autodesk.com

[17] http://www.turbocad.com

[18] http://office.microsoft.com/en-us/visio

[19] A. Bernard, S. Ammar-Khodja, A. Candlot, and N. Perry, "Knowledge Engineering Systems for Digital Enterprise Performance Improvement", In P. F. Cunha, and P. G. Maropoulos (Eds.) "Digital Enterprise Technology", Berlin: Springer, pp.209-216, 2007

[20] N. Perry, and A. Candlot, "Emergence of Symbiotic \& Collaborative Knowledge Networks: how to reach the future work standards?" International Journal on Decision Support Systems, Vol.43, No.4, pp.41$51,2007$.

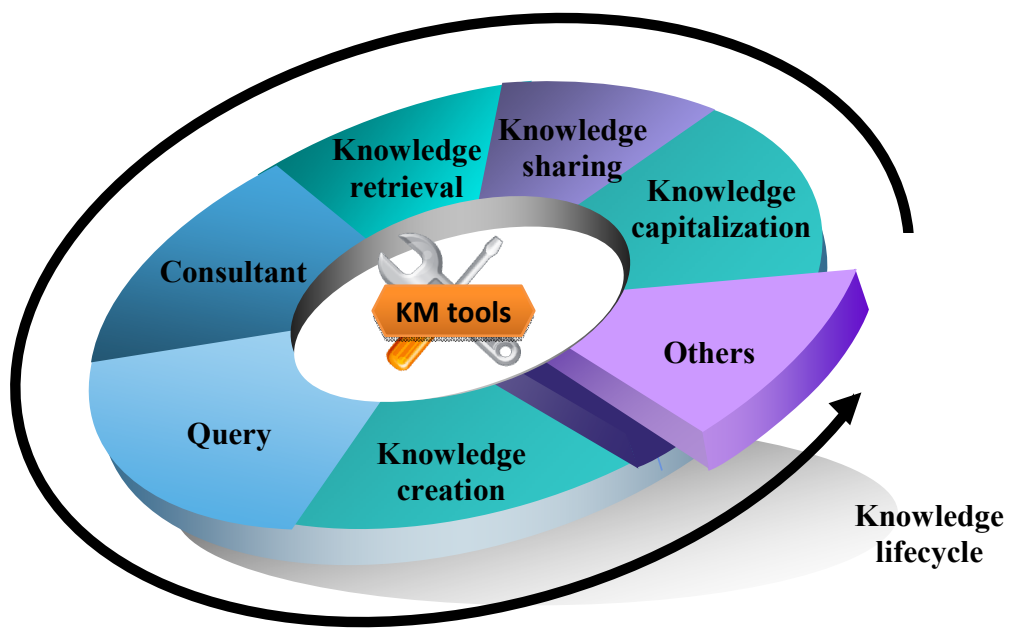

Figure 1. Positioning KM tools in the contet of the knowledge lifecycle 